\title{
Acceptance and Commitment Therapy for Psychosis
}

\author{
Julieann Pankey ${ }^{1}$ and Steven C. Hayes \\ University of Nevada, Reno, USA
}

\begin{abstract}
Although various pharmacological treatments are available for persons suffering with positive psychotic symptoms, these symptoms often continue to occur even when medications are taken. Traditional psychosocial methods such as family therapy and cognitive-behavioral alleviate symptoms in this population, but interventions are often lengthy and difficult. The present paper argues that directly targeting the reduction of psychotic symptoms could produce paradoxical effects, and instead argues for the importance of acceptance, cognitive defusion, and valued action as coping methods. Acceptance and Commitment Therapy is described as such a method, and its outcomes with this population are briefly summarized. A short case on ACT with a psychotic retarded person is presented as an example of the applicability of these methods to persons who are cognitively challenged. Key words: psychosis, Acceptance and Commitment Therapy, Relational Frame Theory; schizophrenia, metaphor, developmentally disabled.
\end{abstract}

\section{RESUMEN}

Terapia de Aceptación y Compromiso aplicada a la psicosis. Aunque varios tratamientos farmacológicos están disponibles para las personas con síntomas psicóticos positivos, estos síntomas continúan a menudo incluso cuando toman la medicación. Los métodos psicosociales tradicionales, como la terapia de familia y la terapia cognitivo-conductual, alivian estos síntomas pero las intervenciones a menudo son largas y difíciles. El presente trabajo expone que intentar reducir directamente los síntomas psicóticos puede producir efectos paradójicos y se propone en su lugar la aceptación, la desactivación cognitiva y la acción orientada a valores como método de enfrentamiento. Se describe el procedimiento de la Terapia de Aceptación y Compromiso y se resumen brevemente sus resultados con esta población. Se presenta un caso breve de ACT con una persona psicótica retardada como ejemplo de aplicación de estos métodos con una persona que está cognitivamente alterada.

Palabras clave: psicosis, Terapia de Aceptación y Compromiso, Teoría de los Marcos Relacionales, esquizofrenia, metáfora, retraso en el desarrollo.

The severely mentally ill (SMI) psychotic population presents difficult and intractable treatment dilemmas for the mental health care system. The economic costs alone represent a considerable burden. In the United States, for example, schizophrenics alone make up about $1 \%$ of the adult population but consume approximately $2.5 \%$ of

${ }^{1}$ Reprints may be obtained from the first author: Department of Psychology 298, University of Nevada, Reno, NV 895570062, USA. E-mail: truebellablue@yahoo.com; hayes@unr.edu. 
the total annual health care expenditures (Rupp \& Keith, 1993) and the economic losses from their disorder account for $2 \%$ of the U. S. gross national product (Maxmen \& Ward, 1995; Wyatt, Henter, Leary \& Taylor, 1991).

SMI patients experience high rates of relapse and re-hospitalization, treatment non-compliance, family burden, financial problems, legal problems, risky behaviors and infectious diseases, violence, suicide, and increased service utilization and service costs (Clark, 1996; Dickey \& Azani, 1996; Dixon, McNary \& Lahman, 1995; Gupta, Hendricks, Kenkel, Bhatia \& Haffle, 1996; Miner, Rosenthal, Hellerstein \& Muenz, 1997; Mueser, Bellack \& Blanchard, 1992; Swartz, Swanson, Hiday, Borum, Wagner \& Burns, 1998). Clinical outcomes for psychotic individuals are made bleaker by the high rate of occurrence of co-morbid disorders. For example, substance use disorders (SUD) afflict upwards of $50 \%$ of the severely mentally ill (SMI) population, and have a profound impact on worsening the course of psychiatric illness (Mueser, Bennett, \& Kushner, 1995). Rates of co-morbid SUD are even higher in subgroups of persons with SMI, such as the homeless, clients with antisocial personality disorder, or those who present for treatment in emergency rooms (Mueser, Rosenberg, Drake, Miles, Wolford, Vidaver \& Carrieri, 1999).

Given the salience of distress across domains of functioning, there exists a pressing need for effective interventions to address this population. By far the most common form of treatment is anti-psychotic medication. While empirically proven psychopharmacological treatments are widely available and effective compared to placebo controls (Davis Schaffer, Killian, Kinard \& Chan, 1980), many patients are unresponsive to medications. Up to $50 \%$ of patients on continuous medications continue to experience positive symptoms, albeit generally at reduced levels, and high levels of side-effects are common (Curson, Patel, Liddle \& Bames, 1988; Kingdon, Turkington \& John, 1994; Silverstein \& Harrow, 1978). Indeed, the grim statistics quoted above are in the context of virtually universal use of neuroleptic medications for this patient group. Something else is needed.

\section{Psychosocial Treatment For Psychosis}

Before the 1970's, there was little evidence from controlled research that any model of psychotherapy (including cognitive behavioral approaches or other methods) could be beneficial for the seemingly intractable behavior experienced by psychotic patients (Penn \& Mueser, 1996). Psychosocial interventions provide an alternative, but the data are limited. Case management, community treatment, family therapy, and skills based approaches are helpful, but they are costly, lengthy, and sometimes of limited effectiveness (Bustillo, Lauriello, Horan \& Keith, 2001; Bustillo, Lauriello \& Keith, 1999; Paul, Stuve \& Menditto, 1997). Cognitive behavior therapy (CBT) is the most researched individual psychosocial approach to date. Several randomized controlled trials of CBT for the treatment of psychotic symptoms have been conducted over the last decade with generally positive results (Kuipers, Garety, Fowler, Dunn, Bebbington, Freeman, \& Hadley, 1997; Tarrier, Kinney, McCarthy, Morris, Humpheys, \& Wittkowski, 2000; Sensky, Turkington, Kingdon, Scott, Siddle, O'Carroll, \& Barnes, 2000). Again, 
however, these studies have been lengthy and costly. They have also combined CBT with other treatment components, such as family intervention, skills training, or enhanced case management (Garety, Fowler \& Kuiper, 2000), so it is not known whether simplified approaches could be effective.

One feature that unites both pharmacotherapy and many currently available psychosocial approaches is their focus on symptoms. The treatment goals of most psychosocial interventions include reducing the frequency, and severity of positive and/ or negative symptoms and facilitating skills to better manage these symptoms (Himadi \& Kaiser, 1991; Tarrier, Yusupoff, Kinney, McCarthy, Gledhill \& Haddock, 1998; Kuipers et al., 1997), improving perceived control over symptoms (Wykes, Parr \& Landau, 1999) and reducing the personal stigma associated with symptoms (Kingdon et al., 1994; Beck \& Rector, 2000).

This symptom focus makes sense given the syndromal emphasis of contemporary perspectives on psychosis. Individuals presenting with psychotic symptoms are categorized in the current nosology based on their behavioral topographies (Maxmen \& Ward, 1995). These include "positive" symptoms such as hallucinations, delusions, and disorganized thought processes and "negative" symptoms, such as emotional or social withdrawal, or blunt affect. In traditional approaches it is the intensity, form, or presence of such symptoms which is presumed to be critical.

There are several reasons to question this perspective. For some individuals the mere presence of symptoms is not distressing (Goff, 2002) and many patients are successful in staying out of the hospital despite the presence of psychotic symptoms (Bustillo et al., 2001). There are practical concerns as well. For example, the most common symptoms of psychotic patients are delusions and hallucinations (Breier \& Berg, 1999). Various features may also be present in the form of adaptive behavior deficits, affective distress, and sensory and memory processing difficulties, however, the core of psychosis seems to rest in the odd cognitions and more specifically, the individual's relationship to those cognitions. An individual with psychosis usually experiences negative private events such as visual or auditory hallucinations and acts out bizarrely in part in an effort to deal with these intrusive private experiences. Over time this seems to result in an unusual internal focus on the part of these patients. For example, SMI patients talk more about disordered thinking, and make more frequent references to their own cognitions than do normal controls (Rosenburg \& Tucker, 1979). Psychosocial interventions that are focused on the modification of private events might thus exacerbate an already excessive inward focus on the part of psychotic patients.

Furthermore, it is possible that directly target psychotic symptoms may sometimes paradoxically increase in them. Research in the area of thought suppression (Wegner, Schneider, Carter \& White, 1987) underscores the possible deleterious effects of targeting private events directly for active control. When normal participants are asked in laboratory experiments not to think about an item the baseline frequency of thoughts about that item tend of rebound above baseline levels. Thus, for example, the attempt to suppress a thought may in fact provide the fuel for the inability to avoid the thought. Thought suppression may set up a state in which people not only increase the amount of time they think about an unwanted thought, but potentially also sharpen emotional reactions 
to those thoughts and provide the beginnings of ruminative symptoms (Gold \& Wegner, 1995). Additionally, mood and suppressed thoughts appear to be "bonded" together in the course of suppression, such that the reactivation of one leads to the reinstatement of the other (Wenzlaff, Wegner \& Klein, 1991). Active attempts to eliminate such symptoms as delusions, autonomic arousal, and auditory hallucinations may exacerbate the problems of the seriously mentally ill (Morrison, 1994; Morrison, Haddock \& Tarrier, 1995). There are some data that comport with the validity of these concerns. For example, Romme and Escher (1993) demonstrated that SMI patients who attempted to distract themselves from auditory hallucinations had poorer outcomes.

\section{Exploring a Contextual Alternative}

A variety of newer behavioral and cognitive therapies have emerged in recent that are focused on acceptance, mindfulness, cognitive defusion, and similar methods (for book length reviews see Hayes, Jacobson, Follette \& Dougher, 1994; Hayes, Follette, \& Linehan, in press). In these methods, there is "little emphasis (...) on changing the content of thoughts; rather, the emphasis is on changing awareness of and relationship to thoughts." (Segal, Teasdale, \& Williams, in press, manuscript p. 13; emphasis in the original). These methods have largely been tested with anxiety, depress, substance abuse, and the like, but there seems to be no reason to suspect that they do not apply to psychosis as well. This type of intervention would focus on altering the believability and behavioral impact of problematic cognitions without directly challenging them or targeting their content for change (Bach \& Hayes, 2002). Rather than an emphasis is on the frequency of symptoms, challenging the veracity of the positive symptoms, or altering the irrationality related to symptoms, the target would be on the individual's relationship to those events.

\section{Acceptance and Commitment Therapy}

One such approach is Acceptance and Commitment Therapy (ACT; Hayes, Strosahl \& Wilson, 1999). The technology has been show to be effective in both short and long protocols, delivered individually or in groups, for a wide variety of problems (see Hayes, Masuda, Bissett, Luoma \& Guerrero, in press, for a recent review). At the level of process, ACT is characterized by a rapid reduction in the believability of negative thoughts or the unacceptability of negative feelings, even if these thoughts and feelings continue at some frequency (Zettle \& Hayes, 1986; Bach \& Hayes, 2002) and thus seems well suited for addressing chronic problems. These two features make ACT of some possible relevance to SMI patients. In what follows we will explain the ACT model and its relevance to psychotic behavior.

\section{Introduction to the ACT / RFT Model}

ACT is based on the core assumption that normal psychological processes, especially those involved with language, can contribute to psychopathology. ACT draws 
from a basic approach to language and cognition: Relational Frame Theory (RFT; Hayes, Barnes-Holmes \& Roche, 2001). According to RFT, derived stimulus relations form the core of human cognition. They have three main properties. First, such relations show mutual entailment. That is, if a person learns in a particular context that A relates in a particular way to $\mathrm{B}$, then this must entail some kind of relation between B and A in that context. For example, if Alan is said to be larger than Bob, then Bob must be smaller than Alan. This property is also called "bi-directionality." Second, such relations show combinatorial entailment: if a person learns in a particular context that A relates in a particular way to $\mathrm{B}$, and $\mathrm{B}$ relates in a particular way to $\mathrm{C}$, then this must entail some kind of mutual relation between $\mathrm{A}$ and $\mathrm{C}$ in that context. For example, if Bob is larger than Charlie then Alan is also larger than Charlie. Finally, such relations enable a transformation of stimulus functions among related stimuli. If you need a person to wrestle with an enemy, and Charlie is known to be valuable, Alan is probably even more valuable. These kinds of derived stimulus functions have been demonstrated with consequential functions (Hayes, Devany, Kohlenberg, Brownstein \& Shelby, 1987; Hayes, Kohlenberg \& Hayes, 1991), antecedent functions (Hayes, Devany, Kohlenberg, Brownstein \& Shelby, 1987), and elicited emotional responses (Dougher, Augustson, Markham \& Greenway, 1994). "Relational frames" are learned patterns of contextually controlled and arbitrarily applicable relational responding involving mutual entailment, combinatorial entailment and the transformation of stimulus functions.

Derived stimulus relations are extraordinarily difficult to break up, even with direct, contradictory training (Wilson \& Hayes, 1996). In other words, once verbal relations are derived, they never seem really to go away. You can add to them, but you cannot eliminate them altogether. Furthermore, derived relational responding will be maintained indefinitely by "sense making." Basic research shows that once we learn how to derive relations among events, we do so constantly as long as we are able to make order out of our world by doing so (e.g., Leonhard \& Hayes, 1991).

Because of the mutual entailment quality of relational frames, when a human interacts verbally with his or her own behavior, the psychological meaning of both the verbal symbol and the behavior itself can change. RFT argues that it is this bi-directional property that makes human self-awareness useful. For example, if an incorrect choice is made, negative evaluation of that choice will alter the function of the original environment when it is next encountered.

This same property of human cognition, however, makes self-awareness painful. A nonhuman can easily be taught a form of self-awareness, but this form will be neither useful nor painful. For example, suppose we teach a pigeon (using food as a consequence) to peck one key after it has been shocked and another after it has not been shocked. We are in effect asking the pigeon whether it has been shocked and the bird is "answering." These answers are not, however, bi-directionally related to the original condition. For that reason, the bird will not learn faster because it reports these consequences, and furthermore, it will report it has been shocked with without any negative emotional arousal being caused by the report. These reports, after all, lead to food, not shock.

Humans are quite different. For the verbally competent human, the word shock, and the actual shock participate in a mutual relation (in this case an equivalence relation), 
and therefore share some stimulus functions. From an RFT perspective, this is why humans often cry when reporting past hurts and traumas even (or perhaps especially) if the report has never been made before. The crying comes because the report is mutually related to the event itself, not because the report itself has been directly associated in the past with aversive events.

This process presents an extreme challenge. A nonhuman trying to avoid pain can avoid the situations in which it occurs. A human cannot because language allows pain to occur in almost any situation through derived relations. In self-defense, humans begin to try to avoid the painful thoughts and feelings themselves - what we term "experiential avoidance," even though this is often destructive in the long run.

Even though this process is harmful, it dominates over other forms of coping because it is supported by evaluative language itself. Verbal rules gradually dominate over other sources of behavioral regulation in humans (what we term "cognitive fusion"). For example, is a study by Hayes, Brownstein, Haas, and Greenway (1986), subjects learned a task either by directly following a rule or by experience. Later on, the task requirements were changed, without any notice being given to the subjects. All of the subjects who learned the task by experience were sensitive to the change, compared to only half of the subjects who originally learned the task by following verbal rules.

This suggests possible ways that the positive symptoms of SMI might have such a negative impact. Patients become entangled in the literal content of their own unusual and at times frightening thoughts and emotions, because contexts that encourage such entanglement are common, while those that weaken it are rare. As entanglement increases, the transfer of negative emotional functions increases. Unfortunately, this is likely to lead to suppression and avoidance, which only increases the functional importance and often the frequency of the avoided thoughts and feelings and results in a more elaborate relational network focused on psychotic symptoms. Because attempts to change verbal relations directly only add new verbal relations and thus elaborate the existing network, a vicious cycle is established. Psychotic symptoms tend to become the focus of many SMI patients lives, and they play a central and destructive role in the regulation of their overt behavior.

Fortunately, RFT also suggests several ways to undermine this destructive process. Rather than attempt to change the content of undesirable perceptions, thoughts, or feelings, RFT suggests that the main way to weaken the negative behavioral impact of these events is to alter the context supporting cognitive fusion and experiential avoidance. ACT is a technology designed to accomplish that end.

\section{ACT AND PsYchosis}

An ACT stance requires a re-thinking of the goals and purposes of traditional psychotherapy. With psychotic individuals, traditional therapy includes support for logical reasoning, the development of evidence for and against distressing beliefs, reality testing, and generating alternative explanations for psychotic symptoms (Kingdon et al., 1994). From an ACT point of view all of these methods are potentially troublesome because they are aimed at changing or eliminating undesirable thoughts, feelings, and bodily 
sensations. Rather, in ACT the goal is changing the function of undesirable thoughts, feelings and bodily sensations. Trying to get rid of thoughts does not change their function: they've had such avoidance functions from the beginning. For example, a client may experience a frightening auditory hallucination, and then begin to do a variety of things (talking back; complying with the voice; trying not to listen to the voice; engaging in physical movements) in an attempt to regulate this aversive experience. In each case, however, the hallucination is now more important, more central, and more able to regulate behavior. ACT instead seeks the development of new responses in the presence of the previously avoided event that diminish its behavior regulatory power, such as being more willing to experience the hallucination as an experience, not as what it says it is, to accept the feelings it occasions, and to focus on over behavior that further ones values and purposes even in the presence of difficult experiences.

\section{ACT Targets for Psychosis}

ACT focuses on the client's original aim of controlling their private experiences and situates willingness and defusion as the vehicles by which individuals learn that acceptance of aversive private emotion or bodily states is a process, not an outcome. The individual learns that through awareness, vulnerability, flexibility, and willingness one can begin to let go of old control agendas (e.g., "buying into" the veracity of delusional ideation) and learn that what needs to change is the stance one has in regard to negative private emotions or bodily states, not the emotion or bodily state itself. ACT shifts the focus from modifying the private experience to modifying one's reaction to the private experience. The goal is to assist the client in embracing more difficult psychological context while simultaneously focusing on valued overt behavior change. A key component to acceptance of private experience is teaching the client to defuse from tangled cognitions. Here, the client learns that the literal truth or falsity of the cognition need not be a target. Instead, the patient is directed toward their goals and behaviors.

The ACT model suggests that the effectiveness, or workability, of the individual's behavior is the key focus. ACT attempts to shape more workable response repertoires based on new response functions. The nature of the new functions that are established is not as important as the process of expanding a constricted repertoire (Hayes and Pankey, 2003).

\section{Core ACT Intervention Methods for Psychosis}

Acceptance and Commitment Therapy is typically composed of several technical components that are designed to help patients drop a needless control agenda, learn to accept difficult private events, learn to defuse from difficult thoughts, to be mindful of the present moment, and to direct behavior toward valued ends. Detailed description of the procedures and theoretical underpinnings can be found book form elsewhere (Hayes et al., 1999; Hayes et al., 2001; Wilson and Luciano, 2002). These technologies apply fairly directly to psychotic patients, although the specific language, metaphors, and 
exercises are modified to fit the population. We will give some examples below.

\section{Dropping the Control Agenda}

The purpose of this ACT component is to begin to destabilize the client's confidence in an active control agenda that is unworkable and to lay the groundwork for more workable ones (Hayes et al., 1999). In some populations this component is intense and experiential, but in psychotic populations we adopt a more psychoeducational and collaborative tone. Patients are asked to examine their experience to see how workable it has been to attempt to control their own mind. They are asked to describe their specific symptoms in detail, including the content, when they tend to occur and not to occur, and how distressing they are to the individual. Patients are asked to look carefully at how they typically respond to these symptoms, and the therapist tries to illuminate needless control efforts. For example, talking back to voices, obeying voices, or taking illicit drugs to cope, are all presented as control efforts. Odd thoughts and perceptions are normalized. Emphasis is placed on the fact that delusional or hallucinatory content is often not very different from thoughts many people have, and that the major difference between the SMI patients and others is how patients respond to these cognitive phenomena. Several examples of thoughts that many people have that are similar to common delusional or hallucinatory themes are often discussed such as fears that one is the target of other's animosity, or grandiose thoughts. The focus is shifted from having the "right" thoughts or feelings, to the possibility that the issue is their relationship to their own thoughts and feelings: the problem is not symptoms per se, but how one responds to them. The unworkability of control is itself treated as a normal process: deliberate control in this area tends to backfire for everyone, not just for SMI patients. Concrete, physical metaphors can be used to illustrate the point. For example, "Chinese handcuffs" (small straw tubes that gab onto fingers when you pull your fingers out) are sometimes played with in session to illustrate that sometimes trying to "escape" can make things worse. Classic ACT metaphors such as the "polygraph metaphor" are also quite useful.

\section{Willingness/Acceptance}

Willingness is presented as an alternative to deliberate control. We asks patients to experience their odd cognitions or disturbing sensory states without taking further steps to change, modify, or control the experience but instead simply to notice that they are aware of these experiences. This may initially be frightening to the client, particularly if some of the sensory experiences they are having have a punishing or aversive quality to them. The therapist normalizes, shares analogous experiences, and "sits with" the client while odd experiences are experienced. The target is not reduction of the frequency of the symptom per se, but rather a change in the client's relationship to that symptom.

\section{Defusion}

The purpose of focusing on cognitive defusion is to help clients who are caught 
up in the content of their own cognitive activity to defuse, or separate themselves, from the literal meaning of thoughts and instead become more aware of thing as an active, ongoing, relational process that is situated both historically and contextually (Luoma \& Hayes, 2003). ACT attempts to weaken the excessive grip of literal meaning through the use of cognitive defusion exercises that shift the client's emphasis from the content of their private experiences to the context. For example, an individual may present with thoughts that the voices they hear are bad and therefore, that they as a person are bad. The individual may become fairly rigid around "rules" about how they "know" what the voices say are "true." ACT cuts around the issue of truth by focusing instead on experience. Metaphors are used to help distinguish the person from their symptoms. For example, we might ask the patient to think of their mind like a television program and to practice just noticing what their mind is saying without arguing back, or trying to figure out if it is "true." It is emphasized that thoughts and feelings cannot directly cause behavior. While one cannot control thoughts and feelings, one can control overt behavior, but that means learning to think thoughts as thoughts. That same message applies to the therapist, not just to the patient, and thus there is a strong normalization message to defusion with these patients.

The essence of ACT defusion strategies is to teach the patient to see thoughts and feelings for what they are (experiences) rather than what they advertise themselves to be (structured reality). Helping the client to understand how language functions in this way can assist them in understanding why they may be experiencing barriers to willingness and to encourage a more flexible way to interact with; and defuse from, excessive or odd cognitions. For example, patients are taught to word thoughts as "I'm having the thought that..." even when the content is bizarre e.g., "I'm having the thought that George Bush is really Satan." This convention helps in recognizing that thoughts, even if experienced as powerful or as outside voices, are merely thoughts that may or may not be useful in guiding action. A wide variety of traditional ACT metaphors (e.g., the bad cup metaphor) are helpful in this defusion work.

\section{Values and Goals}

In ACT the lynchpin of all interventions is the concept of successful working: the notion that patients should engage in behaviors that work best in allowing them to reach their stated goals. For persons with a serious mental illness the attainment of goals often requires experiencing some disturbance from their symptoms in order to remain outside the hospital and pursue their interests. When one responds to symptoms by taking actions that might momentarily ameliorate the symptoms or the distress caused by them there are often negative consequences in relation to other activities such as relationships or employment. In work with psychotic patients, treatment compliance is also raised in the context of having the most behavioral options to pursuing other goals and interests. In our work with psychotic patients, the most frequently reported goals are having a relationship with a significant other, being employed, and living independently. In the values and goals work, patients are asked to explore how past attempts to control symptoms may have interfered with the attainment of their goals. 
For example, a patient may have been evicted from housing for disturbing others when yelling at voices. Acceptance and defusion are thus recast as doing what is in one's best interest in a given situation.

Simple examples are used to link this same process to normal functioning. For example, suppose someone has the thought, "I'm hungry". Whether a person acts on that thought depends on their goals and the situation. If one hasn't eaten in several hours they may decide that it's in their interest to eat. If they're on a diet or if they are going to their favorite restaurant in an hour they may choose to wait a little longer to eat. This same basic stance applies to psychotic symptoms as well.

\section{Fitting ACT Interventions to Psychotic Populations}

ACT interventions involve metaphorical and experiential exercises that demonstrate combinations of the core elements. With psychotic populations we often mix small amounts of several ACT interventions in each session so that the linkage between acceptance, defusion, goals, and actions is obvious. We tend to use interventions that are more concrete, simple, and experiential. A few examples help show how wee approach this task (Pankey, 2003).

\section{The River of Thoughts Metaphor}

* Introduce the notion of thoughts as a part of us that occur on a continuum. Ask the client to begin by drawing on a sheet of paper a huge river designed with big squiggle lines. Ask the client to fill in the river a sample of the "thoughts that they had during the week." Encourage the client to place all thoughts that occur to them within the lines, including "bad" thoughts and "good thoughts."

* Go over the River of Thoughts with the client, discussing the function of the differing thoughts on how the individual perceives their world. Discuss the continuum between psychotic thoughts and other thoughts. Target for the client the distinction between "buying a thought as a fact," and "simply noticing it." Tell the client that the primary problem you are going to work on is not the thoughts per se, but rather how one responds to the thoughts through action, judgments, or active attempts to control the thought.

* Ask the client to imagine floating on a boat in the River of Thoughts, and just simply participating in the ride without attempting to modify the trip. Point out that the action is now one of noticing, rather than active "doing." Use examples which fit the client's experiences to link the theoretical stance related to letting go of struggles and the client's actual struggles with thoughts/bodily sensations/ positive and negative symptoms.

* The focus with this exercise is to begin to disrupt the believability of the thoughts by teaching the client to simply notice but not "buy into as a fact" the veracity of the thought. The client could then have the thought that "Aliens are here on the earth today and I need to exterminate them" without engaging the thought as a fact that needs to be acted on. This assists individuals with defusing from tightly woven stories around delusions and hallucinations and to place these odd cognitions in the flow of one's "river of thoughts" along with other thoughts they are having. The exercise is also meant to help clients begin to be willing to have difficult 
thoughts and to see them as simply thoughts like any other, and not a call to action because of their salience in content.

\section{Down in the Cellar Exercise}

Have the client chose a "well worn" thought that is causing them some distress. Have them imagine that they "hide" the thought downstairs in the cellar of their mind. Have the client get creative in their descriptions, e.g., down the rickety steps, under the aging wood, under a trap door well hidden and covered with blankets and a nice, big, lock and key. Have the client imagine themselves upstairs in the house, wandering around, trying *not* to think about the hidden thought down under the stairs in the cellar. Highlight how trying to "hide" from the thought or to actively "hide" the thought actually makes it more difficult to forget.

\section{Invitation to the Room Exercise}

Now have the client imagine they are sitting in the most comfortable place in the "room of their mind." Have the client detail this room, what it looks, feels, and smells like. Tell the client that the thought that they tried to hide in the cellar is standing outside the door. Are they willing to let the thought come inside? Discuss the paradoxical effects of attempts to keep the door closed. Validate the client's concerns related to fear of opening the door. Suggest that you are willing to sit in there with them, if they are willing. Highlight that "willing to be willing" is the step we want to have them make. It is one step removed from the action of "willing" itself.

* If the client is willing to "let the thought in," have them detail the process, relating feelings of distress and noticing thoughts that their mind is giving them. Have the client notice bodily sensations and any active attempts to control the experience of "letting the thought in the door." Have the client talk about what the thought is doing in the room, whether it is silent, aggressive, what color it is, what shape it is, etc. Encourage them to be creative. If the client is willing, ask them to allow a few "thoughts" to come in the room. Have them describe each one, including how they are all interacting with each other. Normalize and validate distress related to positive and negative symptoms.

* Now that the client is "sitting in the room" with some of their thoughts and has described their physical appearance in detail, introduce a small deck of blank flash cards. Ask the client to write down a brief descriptor of the thoughts on the cards (e.g., "there are purple colored voices," "I am the King of the World"). Once the client has done so, ask the client if they are willing to take one more step towards being willing to put down attempts to control these thoughts. Ask the client if they will either pin the cards to their jacket or carry them in their pocket or purse for the next week. Discuss how being willing to accept negative thoughts and symptoms creates a context whereby "active control" is not necessary anymore. Have the client describe their sense of willingness to complete this homework. Discuss the homework in terms of heightening willingness, acceptance; and awareness to experience. 
Our purpose in giving these examples is to show how to create concrete exercises that are based on ACT concepts, but that simplify them and make them more concrete. We have found that many traditional ACT metaphors and exercises work very well, and that it is not difficult to create new ones where more appropriate versions are needed.

\section{ACT Research on Psychosis}

Controlled research on ACT, while still very limited, provides some support for the use of ACT in a psychotic population. Cases studies have shown promising outcomes for ACT with psychotic patients (García, Luciano, Hernández, \& Zaldivar, in press; García \& Pérez, 2001). A recent randomized trial (Bach \& Hayes, 2002) eighty inpatient psychotic individuals experiencing positive symptoms were randomly assigned to receive four sessions of ACT or treatment as usual (TAU). The ACT interventions closely paralleled the kinds of interventions described in this paper.

Results from this research indicated that ACT participants showed a rate of rehospitalization which cut in half that of the TAU population rate over a four month follow up period, a finding not accounted for by increased medication compliance or decreased experience of psychiatric symptoms. In point of fact, the ACT patients admitted to more psychiatric symptoms. ACT participants showed significantly higher symptom reporting, with 22 ACT subjects (63\%) versus 11 TAU subjects (31\%) admitting symptoms at follow-up. However, although the ACT patients reported more symptoms, those who did so were four times more likely to remain out of the hospital, suggesting that symptom reporting in the ACT condition was in effect a measure of acceptance (Bach \& Hayes, 2002). ACT patients also showed reduced believability in the literal reality of the symptoms they experienced. No ACT patients who both admitted symptoms and showed reduced believability in them were rehospitalized. This suggests that acceptance and defusion may mediate the relationship between symptoms and re-hospitalization, a finding that comports with other research (Morrison \& Baker, 2000) showing that patient interpretation of vocal intrusions are key to their negative effects.

The outcomes for ACT were particularly strong for hallucinating patients, though there were indications that delusion patients were moved as well. A longer intervention may be needed for delusional patients. Hallucinations are often a target of avoidance, while delusions seem sometimes to be a means of avoidance. There was evidence for this interpretation in this study. At baseline in both groups and in follow-up for TAU participants, higher believability of delusions was associated with less distress. However, individuals experiencing delusions in follow-up in the ACT condition no longer showed that pattern suggesting that the defensive and avoidant function of delusions was being removed. If delusions themselves are verbal avoidance strategies, it is not so much the delusional process that needs to be accepted but rather the feelings of failure, depression, anxiety, and so on that the delusions may help regulate (Bach and Hayes, 2002). A longer ACT intervention with such targets might be more useful with delusional patients. A recent successful case study with a delusional patient (García, Luciano, Hernández, $\&$ Zaldivar, in press) provides some empirical support for this idea.

The Bach and Hayes (2002) study is currently being replicated in a dissertation 
and effects through early follow-up closely parallel the earlier findings (Gaudiano \& Herbert, 2003). A larger replication is also being planned by researchers in Australia. It appears as though we will soon know if these early results for ACT are generally replicable.

\section{ACT for Retarded Psychotic Patients: A Case Example}

One of the more promising aspects of this early psychosis work is that it indicates that ACT may be useful even when with patients experiencing significant cognitive disabilities. ACT is sometimes cast by others as a very intellectual treatment, but its heavy reliance on stories and exercises actually seem to recommend it for persons with cognitive problems or developmental delays. In order to see how far this can be taken we have recently begun to test ACT with retarded psychotic populations. The results so far are encouraging.

The present case examined a short, four session psychosis treatment protocol with follow-up for an individual who was diagnosed with schizophrenia undifferentiated and mild mental retardation. Although psychotherapy has been attempted in this population (Wilson, 2001; Hurley \& Silka, 1998), neuroleptic medication is the most common intervention for persons with developmental disability (DD) and co-morbid psychotic illness (Connor \& Posever, 1998; Schwartz, Ruedrich \& McGuire, 1999).

The individual in this case study was a 22 year old Caucasian-Mexican female. She had been taken from her biological parents at age two due to abuse and neglect. She was placed in several foster homes since and had no contact with her natural family. Throughout the duration of the study the patient was living in an intensive supportive living arrangement in an apartment that was staffed 24 hours a day. Staff assisted her with personal hygiene, budgeting, transportation, daily living skills, recreation, and medication compliance. She had a long history of anti-psychotic medications, and during the course of this study was prescribed $15 \mathrm{mg}$ a day of Abilify, a new generation anti-psychotic, $300 \mathrm{mg}$ of Carbatrol, and $15 \mathrm{mg}$ of Benedryl.

On initial consult, this client's self report of her history was grandiose, enhanced, and delusional. Her speech was rambling and tangential. Her affect was serious and labile with smiling and giddiness altering with tears and distractibility. She was aware of day, place, and situation. She had a fairly fluid interpersonal repertoire, listened well, made good eye contact, and had strengths related to continuity and flow of communication. A WAIS assessment of intelligence demonstrated a Verbal IQ of 61, a Performance of 60, and a Full Scale IQ of 58. Her Vineland Adaptive Behavior Scale rating was 40, showing deficits related to communication, daily living skills, socialization, and emotional regulation. There were no known health problems and no substance abuse history.

This client presented with voices that told her to kill herself. She also presented with delusions related to (a) a biological family and children she "gave birth to"; (b) ideas that staff members were part of her family; and (c) a large number of health problems including "leg weakness, heart failure, and seizures." When prompted if there was anything else, the client replied "I am schizophrenic and sometimes I don't know what I am thinking very well." The patient also displayed several troublesome behavior 
patterns, including repeated dismantling of appliances, dysregulated eating, excessive sleep, and poor medication compliance.

Four key outcome measures were identified through discussions with the client and staff. These were (a) compliance with medication, (b) eating, (c) ceasing taking apart her appliances in her apartment, and (d) sleeping. Re-hospitalization was not an outcome target because she was already receiving 24 hour support and had not been hospitalized for over five years.

The ACT intervention followed the approach described in the present paper. Improvement was seen on all outcome measures as assessed by staff and client report. By session three the client was no longer taking apart appliances in her apartment, and was sleeping through the night. Her eating went to the normal range required by staff by session four, and medication compliance was reached by session four. With the exception of medication compliance, none of these targets were directly targeted: the target instead was the patients approach to her symptoms.

Believability, distress, and frequency of symptoms were measured weekly by a 10 point Likert scale. Level of distress showed the most change through the ACT intervention. For example, the client's level of distress related to her auditory hallucinations went from an " 8 " in session one to a " 2 " at the one month follow-up. Although believability in her "health delusion" remained high, all other ratings of believability dropped. By session two, her thoughts that staff were her family members reach zero believability and she reported "zero" distress over this from session two until follow-up. This finding was corroborated by staff, who reported that she told them on various occasions "I know you aren't my family but I wish you were because you are so nice to me." The client's reporting of frequency of hallucinations and delusions remained fairly stable, with Likert scores of fours and fives throughout treatment, with the only decrease being in the delusion that staff were her family. On follow-up, the client still reported that over $60 \%$ of her day she had experienced positive symptoms related to both her hallucinations and delusions. In general, the picture was one of the client expressing symptoms to the therapist and her staff fairly frequently, with the believability and distress related to the symptoms dropping significantly and behavioral outcomes greatly improved.

A simple ACT process measure was used during this case study. The item showing the most movement over treatment was the defusion item "Do you view yourself as separate from your thoughts, feelings, ideas, or bodily sensations." This item was rated at a " 1 " during session one (not at all different) but showed an upward trend to a "4" (a lot different) by follow-up, suggesting that defusion from entanglement with delusions might have been an important mechanism for change. Willingness to experience aversive emotions and the ability to take action to meet behavioral goals also showed significant movement from "somewhat like me" to "very much like me." Although these data are restricted in scope, they are promising in that they suggest that these same ACT strategies might be helpful even with patients who have very limited cognitive abilities. 


\section{CONCLUSION}

There are both huge economic costs and great personal costs to the SMI individuals who experience persistent and recurrent psychotic symptoms. Individuals with psychotic symptoms undergo widespread cognitive difficulties related to sensory impairment, odd cognitions and negative private experiences as well as more instrumental difficulties with the tasks of daily living and other adaptive skills such as social competence, personal health, domestic care, and communication. Because of the salience of both positive and negative symptom profiles, this population has traditionally had difficulty with treatment compliance, high attrition rates, a lack of motivation to access services, and high re-hospitalization rates.

Traditional psychosocial therapy with psychotic population includes directly challenging symptoms. This may increase enmeshment with odd cognitions and symptoms, creating paradoxical rebound effects. ACT is a contextual therapy which targets the individual's relationship to symptoms rather than reduction of symptoms per se. ACT intervenes on the individual's willingness to have symptoms and to not act upon them, defusion from cognitive entanglements, acceptance of symptoms, and a reduction in control attempts designed to avoid private events. Instead, ACT focuses on positive behavior change linked to valued goals. Research on ACT for psychotic disorders is limited but is showing promise.

\section{REFERENCES}

Bach, P. \& Hayes, S.C. (2002). The use of Acceptance and Commitment Therapy to prevent the rehospitalization of psychotic patients: A randomized controlled trial. Journal of Consulting and Clinical Psychology, 70, 1129-1139.

Beck, A.T. \& Rector, N.A. (2000). Cognitive therapy of schizophrenia: A new therapy for the new millennium. American Journal of Psychotherapy, 54, 291-300.

Breier, A. \& Berg, P.H. (1999). The psychosis of schizophrenia: Prevalence, response to atypical antipsychotics, and prediction of outcome. Biological Psychiatry, 46, 361-364.

Bustillo, J.R., Lauriello, J. \& Keith, S.J. (1999). Schizophrenia: Improving outcome. Harvard Review of Psychiatry, 6, 229-240.

Bustillo, J.R., Lauriello, J., Horan, W.P. \& Keith, S.J. (2001). The psychosocial treatment of Schizophrenia: An update. American Journal of Psychiatry, 158, 163-175.

Connor, D.F. \& Posever, T.A. (1998). A brief review of atypical antipsychotics in individuals with developmental disability. Mental Health Aspects of Developmental Disabilities, 1, 93-102.

Curson, D.A., Patel, M., Liddle, P.F. \& Bames, T.R.E. (1988). Psychiatric morbidity of a long stay hospital population with chronic schizophrenia and implications for future community care. British Medical Journal, 297, 819-822.

Davis, J.M., Schaffer, C.B., Killian, G.A, Kinard, C. \& Chan, C. (1980). Important issues in the drug treatment of schizophrenia. Schizophrenia Bulletin, 6, 70-87.

Dickey, B. \& Azeni, H. (1996). Persons with dual diagnoses of substance abuse and major mental 
illness: Their excess costs of psychiatric care. American Journal of Public Health, 86, 973977.

Dixon, L., McNary, S. \& Lahman, A. (1995). Substance abuse and family relationships of persons with severe mental illness. American Journal of Psychiatry, 152, 456-458.

Dougher, M.J., Auguston, E., Markham, M.R., \& Greenway, D.E. (1994). The transfer of respondent eliciting and extinction functions through stimulus equivalence classes. Journal of the Experimental Analysis of Behavior, 62, 331-351.

García, J.M. \& Pérez, M. (2001). ACT as a treatment for psychotic symptoms. The case of auditory hallucinations. Análisis y Modificación de Conducta, 27, 113, 455-472.

García, J.M., Luciano, M.C., Hernández, M. \& Zaldivar, F. (in press). Application of Acceptance and Commitment Therapy to delusional symptomatology: A case study. Psicothema.

Garety, P.A., Fowler, D. \& Kuipers, E. (2000). Cognitive-behavioral therapy for medication-resistant symptoms. Schizophrenia Bulletin, 26, 73-86.

Gaudiano, B.A. \& Herbert, J.D. (2003). Acceptance and Commitment Therapy for psychiatric inpatients. Unpublished manuscript. Department of Psychology, Drexel University, Philadelphia, PA.

Goff, D.C. (2002). A 23 year old man with Schizophrenia. Journal of the American Medical Association, 287 (24), 3249-3257.

Gold, D. B., \& Wegner, D. M. (1995). Origins of ruminative thought: Trauma, incompleteness, nondisclosure, and suppression. Journal of Applied Social Psychology, 25 (14), 1245-1261.

Gupta, S., Hendricks S., Kenkel, A.M., Bhatia, S.C. \& Haffle, E.A. (1996). Relapse in schizophrenia: is there a relationship to substance abuse? Schizophrenia Research, 20, 153-156.

Hayes, S.C. (1994). Content, context, and the types of psychological acceptance. In S.C. Hayes, N.S. Jacobson, V.M Follette \& M.J. Dougher (eds.). Acceptance and change: Content and context in psychotherapy. Reno, NV: Context Press.

Hayes, S.C. \& Pankey, J. (2003). Acceptance. In W. O’ Donohue, J. Fisher, and S.C. Hayes (eds.). Cognitive behavior therapy: Applying empirically supported techniques in your practice. New Jersey: John Wiley \& Sons.

Hayes, S.C., Barnes-Holmes, D. \& Roche, B. (2001). Relational Frame Theory: A post-Skinnerian account of human language and cognition. New York: Plenum Press.

Hayes, S.C., Brownstein, A.J., Haas, J.R. \& Greenway, D.E. (1986). Instructions, multiple schedules, and extinction: Distinguishing rule-governed from schedule controlled behavior. Journal of the Experimental Analysis of Behavior, 46, 137-147.

Hayes, S.C., Devany, J.M., Kohlenberg, B.S., Brownstein, A.J. \& Shelby, J. (1987). Stimulus equivalence and the symbolic control of behavior. Mexican Journal of Behavior Analysis, 13, 361-374.

Hayes, S.C., Follette, V.M. \& Linehan, M. (in press). Mindfulness, acceptance, and relationship. New York: Guilford Press.

Hayes, S.C., Jacobson, N.S., Follette, V.M. \& Dougher, M.J. (1994). Acceptance and change: Content and context in psychotherapy. Reno, NV: Context Press.

Hayes, S.C., Kohlenberg, B.K. \& Hayes, L.J. (1991). The transfer of specific and general consequential functions through simple and conditional equivalence classes. Journal of the Experimental Analysis of Behavior, 56, 119-137.

Hayes, S.C., Masuda, A., Bissett, R., Luoma, J. \& Guerrero, L.F. (in press). DBT, FAP, and ACT: How empirically oriented are the new behavior therapy technologies? Behavior Therapy.

Hayes, S.C., Strosahl, K.D., Wilson, K.G. (1999). Acceptance and commitment therapy: An experiential 
approach to behavior change. New York, NY: The Guilford Press.

Himadi, B. \& Kaiser, J. (1991). Assessment of delusional beliefs during the modification of delusional verbalizations. Behavioral Residential Treatment, 6, 355-366.

Hurley, A.D. \& Silka, V.R. Cognitive-behavioral treatment for panic disorder. Mental Health Aspects of Developmental Disabilities, 1, 119-123.

Kington, D., Turkington, D. \& John, C. (1994). Cognitive behaviour therapy for schizophrenia: The amenability of delusions and hallucinations to reasoning. British Journal of Psychiatry, 164, 581-587.

Kuipers, E., Garety, P., Fowler, D., Dunn, G., Bebbington, P., Freeman, D. \& Hadley, C. (1997). LondonEast Agnlia randomized controlled trial of cognitive-behavioral therapy for psychosis. British Journal of Psychiatry, 171, 319-327.

Leonhard, C. \& Hayes, S.C. (May 1991). Prior inconsistent testing affects equivalence responding. Paper presented at the meeting of the Association for Behavior Analysis, Atlanta.

Luoma, J.B. \& Hayes, S.C. (2003). Cognitive defusion. In W. O' Donohue, J. Fisher, and S.C. Hayes (eds.). Cognitive behavior therapy: Applying empirically supported techniques in your practice. New Jersey: John Wiley \& Sons.

Maxmen, J.S., \& Ward, N.G. (1995). Essential psychopathology and its treatment. New York: W.W. Norton \& Company.

Miner, C.R., Rosenthal, R.N., Hellerstein, D.J. \& Muenz, L.R. (1997). Prediction of compliance with outpatient referral in patients with schizophrenia and psychoactive substance use disorders. Archives of General Psychiatry, 54, 706-712.

Morrison, A.P. (1994). Cognitive behaviour therapy for auditory hallucinations without concurrent medication: A single case. Behavioural and Cognitive Psychotherapy, 22, 259-264.

Morrison, A.P. \& Baker, C.A. (2000). Intrusive thoughts and auditory hallucinations: A comparative study of intrusions in psychosis. Behavior Research and Therapy, 38, 1097-1106.

Morrison, A.P., Haddock, G. \& Tarrier, N. (1995). Intrusive thoughts and auditory hallucinations: A cognitive approach. Behavioural and Cognitive Psychotherapy, 23, 265-280.

Mueser, K.T., Bellack , A.S., \& Blanchard, J.J. (1992). Comorbidity of Schizophrenia and substance abuse: Implications for treatment. Journal of Consulting and Clinical Psychology, 60, 845856.

Mueser, K.T., Bennett, M. \& Kushner, M.G. (1995). Epidemiology of substance use disorders among persons with chronic mental illnesses. In A.F. Lehman \& L. Dixson (eds.). Double jeopardy: Chronic mental illness and substance abuse in persons with severe mental illness. New York: Harwood Academic Publishers. (pp. 9-25)

Mueser, K.T., Rosenberg, S.D., Drake, R.E., Miles, K.M., Wolford, G., Vidaver, R. \& Carrieri, K. (1999). Conduct disorder, antisocial personality disorder, and substance use disorders in schizophrenia and major affective disorders. Journal of Studies on Alcohol, 60, 278-284.

Paul, G.L., Stuve, P. \& Menditto, A.A. (1997). Social-learning program (with token economy) for adult psychiatric impatients. The Clinical Psychologist, 50, 14-17.

Penn, D.L., \& Mueser, K.T. (1996). Research update on the psychosocial treatment of Schizophrenia. American Journal of Psychiatry, 153, 607-617.

Rosenberg, S.D. \& Tucker, G.J. (1979). Verbal behavior and schizophrenia: The semantic dimension. Archives of General Psychiatry, 36, 1331-1337. 
Rupp, A. \& Keith, S.J. (1993). The costs of schizophrenia. Schizophrenia, 16, 413-423.

Schwartz, S.A., Ruedrich, S.L. \& McGuire, P. (1999). Decision-making in the delivery of clinical services to persons with developmental disabilities. Mental Health Aspects of Developmental Disabilities, 2, 95-102.

Segal, Z.V., Teasdale, J.D. \& Williams, J.M.G. (in press). Mindfulness-based cognitive therapy: An integrative approach for prevention of relapse in depression. In S.C. Hayes, V.M. Follette, M. \& Linehan (Eds.). Mindfulness, acceptance, and relationship: Expanding the cognitive behavioral tradition. New York: Guilford Press.

Sensky, T., Turkington, D., Kingdon D., Scott, J., Siddle, R., O’Carroll, M. \& Barnes, T. (2000). A randomized controlled trial of cognitive-behavioral therapy for persistent symptoms in schizophrenia resistant to medication. Archives of General Psychiatry, 57, 165-172.

Silverstein, M.L. \& Harrow, M. (1978). First rank symptoms in the post acute schizophrenic: A followup study. American Journal of Psychiatry, 135, 1418-1426.

Swartz, M.S., Swanson, J.W., Hiday, V.A., Borum, R., Wagner, H.R. \& Burns, B.J. (1998). Violence and mental illness: The effects of substance abuse and nonadherence to medication. American Journal of Psychiatry, 155, 226-231.

Tarrier, N., Kinney, C., McCarthy, E., Morris, J., Humpheys, L. \& Wittkowski, A. (2000). Two-year follow-up of cognitive-behavioral therapy and supportive counseling in the treatment of persistent symptoms in chronic schizophrenia. Journal of Consulting and Clinical Psychology, 68, 917-922.

Tarrier, N., Yusupoff, L., Kinney, C., McCarthy, E., Gledhill, A., Haddock, G., \& Morris, J. (1998). Randomized controlled trial of intensive cognitive behaviour therapy for patients with chronic schizophrenia. British Medical Journal, 317, 303-307.

Wegner, D.M., Schneider, D.J., Carter, S.R.III \& White, L. (1987). Paradoxical effects of thought suppression. Journal of Personality and Social Psychology 53, 5-13.

Wenzlaff, R.M., Wegner, D.M. \& Klein, S. B. (1991). The role of thought suppression in the bonding of thought and mood. Journal of Personality and Social Psychology 60, 500-508.

Wilson, S.R. (2001). A four-stage model for management of Borderline Personality Disorder in people with mental retardation. Mental Health Aspects of Developmental Disabilities, 4, 68-76.

Wilson, K.G. \& Hayes, S.C. (1996). Resurgence of derived stimulus relations. Journal of the Experimental Analysis of Behavior, 66, 267-281.

Wilson, K.G. \& Luciano, C. (2002). Terapia de Aceptación y Compromiso -ACT. Un tratamiento conductual orientado a los valores. Madrid: Pirámide.

Wyatt, R. J., Henter, I., Leary, M.C., \& Taylor, E. (1995). An economic evaluation of schizophrenia1991. Social Psychiatry and Psychiatric Epidemiology, 30, 196-205.

Wykes, T., Parr, A.M., \& Landau, S. (1999). Group treatment of auditory hallucinations. British Journal of Psychiatry, 175, 180-185.

Zettle, R.D. \& Hayes, S.C. (1987). Dysfunctional control by client verbal behavior: The context of reason giving. The Analysis of Verbal Behavior, 4, 30-38. 